\title{
OS MÚLTIPLOS SENTIDOS DA TELEVISÃO NA CONTEMPORANEIDADE: LINGUAGEM, CONTEÚDO, MIIDIA E SUBJETIVIDADE
}

\author{
The multiple meanings of contemporary television: \\ language, content, medium, and subjectivity
}

Los múltiples significados de la televisión contemporánea: lenguaje, contenido, medios y subjetividad

\author{
Roberto Schmidt \\ Pontifícia Universidade Católica de São Paulo, São Paulo, Brasil \\ Doutor em Comunicação e Semiótica pela Pontifícia Universidade Católica de São Paulo (PUC-SP). \\ Mestre em Comunicação e Semiótica pela PUC-SP. \\ E-mail: robertolasalviaschmidt@gmail.com
}

\section{Clotilde Perez}

Universidade de São Paulo, São Paulo, Brasil

Professora titular da Escola de Comunicações e Artes da Universidade de São Paulo (ECA-USP).

Livre-docente em Ciências da Comunicação pela USP. Doutora em Comunicação e Semiótica pela PUC-SP.

E-mail: cloperez@usp.br

RESUMO Este artigo busca articular os conhecimentos sobre televisão de uma perspectiva hibridizada de veículo, linguagem e conteúdo a partir das proposições teóricas de De Botton e Armstrong para o entendimento da arte como instrumento terapêutico. Tal aproximação possibilita a expansão do papel da arte em construção de subjetividade para o universo da produção televisiva, pareando-a como potencialidade favorável com as funções da arte descritas pelos autores - rememoração, esperança, sofrimento, reequilíbrio, compreensão de si, crescimento e apreciação.

PALAVRAS-CHAVE Hibridização, Televisão, Arte, Construção de subjetividade, Instrumento terapêutico.

\begin{abstract}
This article seeks to articulate knowledge about television from a hybridized perspective of vehicle, language, and content, based on the theoretical propositions of De Botton and Armstrong for the understanding of art as a therapeutic tool. This approach allows for the expansion of the role of art in the construction of subjectivity for the universe of content in television production, putting it on par, as favorable potentiality, with the functions of art described by the authors - remembrance, hope, suffering, rebalancing, self-understanding, growth, and appreciation.
\end{abstract}

KEYWORDS Hybridization, Television, Art, Construction of subjectivity, Therapeutic instrument.

RESUMEN Este artículo busca articular el conocimiento sobre la televisión en su perspectiva híbrida de vehículo, lenguaje y contenido con las propuestas teóricas de De Botton y Armstrong para comprender el arte como herramienta terapéutica. Este enfoque permite ampliar el papel del arte como construcción de subjetividad para el universo en la producción televisiva, emparejándola como potencialidad favorable con las funciones del arte descritas por los autores: recuerdo, esperanza, sufrimiento, reequilibrio, autocomprensión, crecimiento y apreciación.

PALABRAS-CLAVE Hibridación, Televisión, Arte, Construcción de subjetividad, Instrumento terapéutico.

\section{Como citar este artigo:}

SCHMIDT, R.; PEREZ, C. Os múltiplos sentidos da televisão na contemporaneidade: linguagem, conteúdo, mídia e subjetividade. Signos do Consumo, São Paulo, v. 13, n. 2, jul./dez. p.1-13. 2021 


\section{INTRODUÇÃO}

A televisão no Brasil completou 70 anos em 2020 e teve muitos motivos para celebrar. De fetiche inspirador de teorias longevas, como descrito em McLuhan (1964), passou a veículo central nas campanhas publicitárias de todas as categorias nos anos 1970, 1980 e 1990, gerando premiações internacionais e enriquecimento do sistema publicitário.

Brennan (2016) nos lembra que, por outro lado, desde a invenção da TV, ela tem sido acusada de destruir a integridade física dos seres humanos e influenciar negativamente a sociedade. Da destruição das células cerebrais à obesidade, da lavagem cerebral ao emburrecimento, do aumento da criminalidade ao esfacelamento do conceito de comunidade, a TV já apareceu como vilã em diversos momentos e narrativas.

A TV adentrou o novo milênio com previsões assustadoras acerca de seu desgaste, obsolescência e morte, na melhor expressão apocalíptica. Nesse sentido, uma das referências teratológicas bastante impactantes está em Negroponte e sua obra $A$ vida digital (1995). É fácil também encontrar na internet diversos artigos declarando o final da TV, como aparelho, como sistema de transmissão ou como conteúdo.

No entanto, segundo Brennan (2016), "todo novo canal de mídia ou inovação tecnológica atrai revolucionários a proclamar a morte de tudo que veio antes” (p. 54). Como bem afirmam Briggs e Burke (2004), a mídia se caracteriza pelo empilhamento e não pela substituição imediata ou desaparecimento. Empilhamento que permite trocas, misturas e transformações. Esse preceito teórico fica evidente quando constatamos, por exemplo, que a televisão pautou a principal plataforma de vídeos da internet mundial, o YouTube, que significa literalmente "você no tubo" ou "você na televisão", importando não apenas a referência nominativa metonímica, como também suas lógicas e linguagens: vinhetas de abertura e encerramento, frequência, grade, canais etc.

Em uma pesquisa realizada em $2018^{1}$ com foco no entendimento e nas práticas dos youtubers, constatamos que a televisão era central nos discursos, nas formas de expressão, inspiração e até na presença física nos vídeos sobre a vida privada, principalmente aqueles de início de carreira. Isso mostra que até a dimensão da materialidade da televisão continua muito forte, mesmo no cotidiano daqueles que apresentam um novo modo de trabalho e de vida: os criadores de conteúdo para as redes sociais.

O que notamos é que a televisão do século XXI está se hibridizando, misturando as instâncias de veículo/mídia, organização/empresa e linguagem/conteúdo, com predomínio da última sobre as demais. A linguagem televisiva, expressa no conteúdo produzido, transita e se expande nas mais diversas mídias/telas e fora delas, em ações de rua, eventos e experiências diversas, como bem formularam Jenkins, Ford e Green (2013) no livro Spreadable Media; Gitlin (2003), em suas referências às mídias sem limite, e Brennan (2016), em suas referências às qualidades da TV analógica e sua capacidade de criar uma super mídia digital, como de fato estamos constatando.

No entanto, o que fazer perante as posições quanto ao caráter emparvecedor, vulgar ou destrutivo da TV? Apesar de toda a capacidade de alcance, de expansão do conteúdo para fora da tela e de conexão social, seu entendimento deve estar restrito como meio publicitário ou como apenas gerador de conteúdo jornalístico ou de entretenimento?

1. Pesquisa realizada pela Casa Semio para o Grupo Globo: os jovens na contemporaneidade, capítulo youtubers e a produção de conteúdo. 
O prefácio do livro Tudo sobre arte (2011), de Stephen Farthing, traz Richard Cork, historiador da arte, crítico, editor, curador e apresentador de televisão no Reino Unido, afirmando que "se permanecermos diante da obra [de arte] e permitirmos que ela se infiltre em nossa consciência aos poucos, talvez seja possível que ocorra uma comunhão reveladora entre a arte e o espectador” (p. 7). Poderíamos pensar que a TV tem papel semelhante frente ao telespectador, assemelhando-se às influências e reflexões da arte?

Na expressão do conteúdo, principalmente na produção audiovisual, acreditamos que a televisão se manifesta como arte, articulando técnicas de cenografia, representação dos atores, textos, músicas, luzes, sempre no melhor sentido da criação de uma obra que sensibiliza e, por isso, ensina nossos sentidos. Santaella (2013) afirma ser a hipermídia a linguagem típica da era digital, misturando "linguagens, processos sígnicos, códigos e mídias” (p. 198). Também a televisão instaurou a mistura da imagem em movimento com o som e o verbo, como no cinema, inicialmente no conforto e na familiaridade das casas, e atualmente em computadores, tablets e smartphones. Assim, a televisão, pela sua natureza amalgamada, continua seu processo de mistura, abrindo-se às potencialidades do digital com ênfase para a participação e a conexão permanente, favorecendo a comunicação ubíqua.

Alain de Botton e John Armstrong, em seu livro Arte como terapia (2014), sinalizam que, desde o século passado, a relação entre as pessoas fora do círculo dos críticos, estudantes e especialistas com a arte "tem se enfraquecido por causa de uma profunda relutância institucional em responder para que ela serve” (p. 4). Para os autores, a arte pode ser entendida e definida, em termos simples, como um instrumento terapêutico com capacidade de fazer bem para as pessoas, a partir de sete funções por eles listadas - rememoração, esperança, sofrimento, reequilíbrio, compreensão de si, crescimento e apreciação. Será que a TV tem os mesmos predicados e potencialidades?

Assim, inspirados no conhecimento teórico e empírico sobre a TV brasileira, as teorias da comunicação e linguagem aplicadas a esse contexto (BRENNAN, 2016; BRIGGS; BURKE, 2004; JENKINS; FORD; GREEN, 2013; MACHADO, 2000; SANTAELLA, 2007, 2013; WILLIAMS, 2016), seguiremos os passos da discussão e reflexão de Alain de Botton e John Armstrong (2014) sobre a arte como caminho terapêutico, buscando a possibilidade do entendimento da televisão como arte mediadora e problematizando os múltiplos sentidos da televisão contemporânea, engendrando aspectos das linguagens hibridizadas e das artes, em um contexto midiático espraiado, conectado e ubíquo.

\section{TELEVISÃO COMO ARTE MEDIADORA}

No que tange à televisão, as discussões ganham uma diversidade de possíveis abordagens, das questões tecnológicas às culturais, passando por metrificação, impactos sociais, história e assim por diante. No entanto, está claro que esse meio não morreu nem foi substituído por outras plataformas. Briggs e Burke (2004) apontam que as eras dos meios, como o da radiodifusão, da televisão ou do cinema, "sobrepuseram-se uma à outra” e "nenhum meio eliminou o outro" (p. 263).

Brennan (2016) indica que o sucesso prolongado da televisão como meio de comunicação está no seu poder de "gerar os sentimentos associados a experiências de outras pessoas” (p. 108) e reitera essa 
afirmação ao dizer que "o que vemos na tela afeta profundamente a forma como nos sentimos” (p. 109).

Ao discutir diferentes formas de abordar a televisão, Machado (2000) aponta que ela pode ser entendida como um dispositivo "através do qual uma civilização pode exprimir a seus contemporâneos os seus próprios anseios e dúvidas, as suas crenças e desgraças, as suas inquietações, as suas descobertas e os voos de sua imaginação” (p. 11). Mas tais expressões não seriam as tipicamente encontradas na arte?

Fala-se em arte em muitos sentidos. É comum encontrarmos o uso do termo em a "arte do escritor", a "arte de viver", a "arte da cozinha" e a "arte da atriz", por exemplo. Nessa formulação, a arte tem sentido de execução, de habilidade para produzir algo, de ação intencional de um artífice especializado, de representação de um ator preparado. Todos esses sentidos estão alinhados com a tradição do pensamento grego. É a arte como téchne, compreendida como uma forma de conhecimento, incorporando outras dimensões, além dos vínculos próprios do fazer especializado, habilidade ou destreza para produzir algo.

Ao falar de arte, certamente nos deparamos com uma ampla gama de atividades, como a pintura, a escultura, a poesia, a literatura, a música, o teatro e a dança, só para citar algumas, dentre aquelas entendidas como tradicionais. Soma-se a isso uma extensa discussão sobre o que é arte, sobre o que não é arte e até sobre a possibilidade de defini-la. É a forma, o processo, o artista, o crítico, a estética, a materialidade, a função, a intencionalidade ou a institucionalidade que define a arte? Não nos cabe aqui nem tentar desbravar essa hercúlea tarefa de transitar pela longa história da arte e seus diferentes movimentos artísticos, nem comparar a visão sobre o tema dentre muitos autores e filósofos, e muito menos, defini-la. Não é esse o nosso propósito. No entanto, voltaremos nosso olhar para os efeitos da experiência resultante do contato com a arte permitida pela televisão. Na exposição do indivíduo a algum tipo de manifestação artística, ele vivencia a particularidade desse encontro. Aristóteles (2002) nos diz que "a experiência é conhecimento dos particulares, enquanto a arte é conhecimento dos universais" (p. 5).

Adensando nossas reflexões sobre arte em outras perspectivas, examinamos o livro Arte como terapia, de Alain de Botton e John Armstrong (2014). Nele, os autores propõem uma visão instrumental da arte, utilizando-a como "meio terapêutico que pode ajudar a guiar, incentivar e consolar o espectador, permitindo-lhe evoluir" (p. 5). Partindo dessa iniciativa, os autores detalham sete funções da arte, cujos efeitos atenuariam algumas fragilidades inatas ou psicológicas dos seres humanos. São elas: rememoração, esperança, sofrimento, reequilíbrio, compreensão de si, crescimento e apreciação.

Os autores têm a convicção de que o envolvimento com a arte pode nos ajudar a refletir sobre a necessidade de esquecermos o que é preciso esquecer e lembrarmos de experiências relevantes; falam sobre a importância de termos esperança e seguirmos em frente, apesar das intempéries que a vida traz; sobre a sensação de isolamento e solidão ao enfrentar as dores e o sofrimento; sobre a dificuldade de enxergamos o melhor de nós dentre os nossos múltiplos eus; sobre a complexidade de entendermos quem somos e como nos apresentamos para o mundo; sobre as nossas avaliações superficiais e preconceituosas; e sobre a mercantilização que destaca o glamour e a percepção de que a verdadeira vida está em outro lugar e não diante de nós (DE BOTTON; ARMSTRONG, 2014, p. 64). Nessa abordagem, a arte tem a capacidade de atuar como mediação para uma condição melhor. 
Quando nos aproximamos do entendimento da televisão como arte, podemos constatar a rentabilidade dessa possibilidade. Assim, partindo as funções da arte propostas por De Botton e Armstrong (2014), entenderíamos que a potencialidade da experiência televisiva "mantém à vista as coisas alegres e agradáveis"; "nos lembra o lugar legítimo do sofrimento numa boa vida"; "codifica com invulgar clareza a essência das nossas boas qualidades"; "pode nos ajudar a identificar o que é central para nós, mas difícil de expressar em palavras” (p. 65). Ainda, a televisão como arte mediadora "pode nos oferecer alguns dos exemplos mais eloquentes das vozes de outras culturas"; além de renovar "nossa casca” e nos salvar do "habitual descaso pelo que está ao redor” (p. 65).

\section{EFEITOS DAS SETE FUNÇÕES DA ARTE}

O entendimento das funções da arte apontadas por De Botton e Armstrong (2014) nos inspirou no sentido de compreender a televisão, na sua potência como conteúdo, expressão e linguagem, como arte mediadora de uma melhor relação com nós mesmos e nossa subjetividade e com nosso entorno, possibilitando diálogos, produções e vivências midiáticas amplas e significativas. Vejamos cada um dos sete caminhos.

\section{TV como rememoração}

O conteúdo que vemos na TV não trata apenas de qualquer coisa alheia a nós, de histórias de outros lugares ou de pessoas que não conhecemos. São paixões e afetos como os nossos, são experiências como as nossas, são jornadas de vida como as nossas, na produção de entretenimento e no jornalismo. Quando queremos lembrar do que realmente foi e é importante na nossa história de vida, a TV é uma forma de preservar e reativar essas memórias, nos ajudando a lembrá-las e, em alguma medida, revivê-las.

Entregamo-nos mentalmente a elas e, por algum tempo, sentimo-nos aliviados das preocupações, imersos num contexto mais amplo que interrompe as reclamações incessantes do nosso ego. (DE BOTTON; ARMSTRONG, 2014. p. 65)

Revivemos de diferentes formas as mesmas histórias de lutas de classes, de aceitação ou de conquistas, de amores platônicos, ardentes ou impossíveis e de caminhos alegres ou tortuosos na busca da nossa identidade. Em cada nova versão, reencontramos experiências vividas na infância, primeiros amores e grandes aprendizados. O cinema é rico em exemplos dessas histórias, mas é na TV que elas ganham contato com o grande público, com as massas, seja em sessões de filmes, nas telenovelas, nas séries ou até mesmo nos anúncios publicitários.

O rever conteúdos já conhecidos, por sua vez, nos transporta a um tempo mais seguro, a um ambiente familiar e relativamente previsível. Permite-nos reativar nossa memória e compartilhá-la com outras pessoas, dividindo as experiências de um passado filtrado pelo tempo e pelos sentimentos sedimentados e apaziguados. Os conteúdos audiovisuais de reprises das telenovelas no Vale a Pena Ver de Novo, no ar na TV Globo desde 1980, ou no canal Viva, na TV por assinatura desde 2010, com seus personagens, atores, histórias, lugares e trilhas sonoras, recuperam as dimensões semânticas, musicais e estéticas da época, como as roupas, a moda, a maquiagem, os cortes de cabelo e os ambientes 
domésticos, jargões e trilhas sonoras, por exemplo. Da mesma forma, gerações se divertem ainda com as trapalhadas de Roberto Gómez Bolaños interpretando Chaves (El Chavo) e com as maluquices do Pica-Pau nos desenhos animados. As audiências desses produtos reprisados indicam o valor da memória e do conforto que o reviver permite. A Viagem, por exemplo, telenovela produzida pela Globo, exibida originalmente em 1994, foi reexibida pela primeira vez em 2105 pelo Viva, canal por assinatura do Grupo Globo, e pela segunda vez entre dezembro de 2020 e julho de 2021. Mesmo tendo sido exibida anteriormente, a última reprise assumiu a liderança de audiência em TV por assinatura nas faixas horárias vespertina e noturna, segundo o próprio canal Viva.

Fato a se destacar foi o sucesso das reapresentações de telenovelas em TV aberta durante a pandemia. Com as restrições implantadas em março de 2020, as produções de Amor de Mãe e Salve-se Quem Puder foram interrompidas e, em seus lugares, foram exibidas, respectivamente, Fina Estampa, telenovela exibida originalmente em 2011, e Totalmente Demais, de 2015. Em 2021, no slot da novela das 21h, foi reprisada a telenovela Império, cuja versão original esteve no ar entre 2014 e 2015. Essa reexibição, segundo informações do canal, alcançou 128 milhões de pessoas no primeiro mês de veiculação e foi líder de audiência.

Nesses momentos, voltamos ao passado e lembramos que alguém em nossa família tinha tal modelo de automóvel, que fulano também usava determinado corte de cabelo, como era bela aquela atriz ou como nos divertimos dançando ao som de uma música que fez sucesso.

\section{TV como esperança}

A psicologia, a fé, a filosofia ou a bioquímica explicam, cada uma a sua maneira, o que nos dá a energia para levantar da cama a cada dia e enfrentar o mundo, com todas as suas incertezas, dificuldades, perdas e até finitude, e que têm como contraponto os gestos carinhosos, os sucessos e as pontuais realizações. No entanto, talvez para grande parte das pessoas, a balança tende para uma história de vida marcada por frustrações, por uma visão de mundo que ainda amarga guerras, doenças e fome, por uma jornada pessoal fadada a ser tocada pela dor da perda de pessoas queridas. "Os problemas do mundo nos são apresentados com tanta frequência que precisamos de instrumentos para preservar o ânimo" (DE BOTTON; ARMSTRONG, 2014, p. 16). E é esse o lugar da esperança e de, sempre que possível, trocarmos nossas lentes para tentar ver alguma beleza e rir daquilo que nos circunda, já que a realidade é composta tanto por facetas de injustiças e de preocupações quanto por beleza e graça, que a televisão pode assumir. A televisão tem a potencialidade de se abrir como uma janela para os telespectadores, mostrando lugares, ações, histórias, tempos e pessoas que materializam a possibilidade da alegria, de diferentes manifestações do belo, do elogio e de uma existência serena ou eufórica. E é prerrogativa desse consumidor de mídia decidir se espera que tal janela se abra fortuitamente ou se ativamente busca por ela nos diferentes canais da TV aberta, no amplo cardápio dos canais de TV por assinatura ou em alguma plataforma de streaming.

"Se o mundo fosse um lugar melhor, talvez nos sentíssemos menos comovidos e tivéssemos menos necessidade de obras graciosas", nos lembram De Botton e Armstrong (2014, p. 16). Quando falamos de esperança, não nos limitamos às expressões do belo, seja nos grandes projetos cinematográficos das sessões ou canais de filmes, nos elaborados documentários sobre artistas, exposições e poetas, nos programas, 
quadros ou canais dedicados à majestosa natureza, com toda a sua representação na geologia, na fauna ou na flora, ou na simples qualidade visual, sonora, de roteiro e de interpretação de séries e telenovelas. A esperança se encontra na contemplação dos atos de bondade e de justiça. Eco (2004) nos diz que, "mesmo quando consideramos boa uma ação virtuosa, gostaríamos de tê-la realizado nós mesmos [...]” (p. 8). Tais exemplos habitam os telejornais ou programas e quadros específicos, como o Teleton, a Porta de Esperança e o Construindo um Sonho, do SBT; o Criança Esperança, o Lata-Velha e o Lar Doce Lar, da Globo; a Hora da Virada, da RecordTV, e tantos outros.

A esperança, como potência, destino ou força motriz, é amplamente trabalhada nos canais ancorados em valores religiosos de diferentes doutrinas ou fés, também em faixas horárias cedidas ou comercializadas pelos canais convencionais. A esperança ainda é inerente às transmissões das mais variadas modalidades esportivas, em que o público anseia por um resultado positivo ou, melhor ainda, pela vitória dos seus times, do seu país ou do seu atleta do coração. A TV é um caminho privilegiado para o incentivo e a vivência desse sentimento tão importante para nosso equilíbrio psíquico.

De Botton e Armstrong (2014) também sinalizam a relação entre a experiência do riso, a agradabilidade e a esperança: "aceitamos muito bem a ideia, exemplificada pela caricatura, de que o exagero e simplificação nos dão vislumbres valiosos que se perdem ou se diluem na experiência do cotidiano” (p. 22). A caricatura tem muito a nos ensinar sobre a importância das representações simbólicas do mundo para nós. A risada e o humor dão uma pausa nas trepidações do dia a dia, entregam a possibilidade de amenizar os conflitos de todas as espécies e expõem ao ridículo situações corriqueiras (EAGLETON, 2020; WEEMS, 2016). Aqui há ampla variedade de exemplos de quadros, programas e séries que recorrem a essa estratégia em prol de abrir caminho frente às dificuldades da vida.

Eco (2004) nos diz que "com base na nossa experiência cotidiana, tendemos a definir como bom tudo aquilo que não somente nos agrada, mas também que gostaríamos de ter” (p. 8). Dessa forma, a televisão, por meio de sua carga de comerciais, patrocínios e ações no conteúdo, por exemplo, além de janela, também é uma porta para a possibilidade de consumo. A publicidade, suas estratégias e táticas, como nos lembra Perez (2017), nesse meio, vão ao encontro da esperança do público de ter suas necessidades e desejos satisfeitos, do prazer de consumir, da minimização do esforço com esse consumo e com a facilitação de sua aquisição. O consumo é um caminho de satisfação, transitório, mas certamente muito presente, factível e inevitável nas sociedades capitalistas (PEREZ, 2020).

\section{TV como sofrimento}

De Botton e Armstrong (2014) nos dizem que "muitas coisas ficam ainda piores porque achamos que somos os únicos a sofrer" (p. 26). A percepção de que as desgraças, dores e tristezas do mundo só acontecem conosco ou que ninguém jamais passou pelas mesmas agruras pelas quais passamos, é um fenômeno inegável. "Sentimos a nossa desgraça como uma maldição ou como a demonstração do nosso caráter maldoso e degenerado" (DE BOTTON; ARMSTRONG, 2014, p. 26), refletem os autores.

No entanto, o enfrentamento das dificuldades e dos obstáculos faz parte da jornada humana. Tanto a religião como a filosofia e a psicanálise tocam no tema do sofrimento, de diferentes formas, mostrando sua 
naturalidade ou inevitabilidade e seu aspecto impulsionador para a nossa reflexão e crescimento, como podemos observar nas reflexões de Schopenhauer (1985):

Trabalho, tormento, desgosto e miséria, tal é sem dúvida durante a vida inteira o quinhão de quase todos os homens. Mas se todos os desejos, apenas formados, fossem imediatamente realizados, com que se preencheria a vida humana, em que empregaria o tempo?. (p. 23)

Nesse ambiente, a televisão proporciona um espaço permanente para nos deparamos com as dores do mundo, tal como o próprio título do livro de Schopenhauer. Percebemos que as aflições que nos acometem também são vividas por outros e que há dificuldades que não enfrentamos, mas sentimos empatia por personagens ou por pessoas reais que passam por tais situações.

É inevitável lembrar da personagem Camila Ferrari, interpretada por Carolina Dieckmann, na novela Laços de Família, exibida na Globo pela primeira vez entre os anos 2000 e 2001. Camila fica grávida de Edu, interpretado por Reynaldo Gianecchini, mas descobre que está sofrendo de leucemia e perde o bebê. Icônica é a cena em que a personagem chora copiosamente enquanto tem seu cabelo raspado para iniciar o tratamento quimioterápico. Outras tantas novelas, séries e filmes trazem a experiência da dor alheia como fio condutor de suas narrativas ficcionais. Na mesma direção, os telejornais, por sua vez, seja na cobertura de desastres naturais, seja acompanhando acidentes ou desgraças cotidianas das mais variadas proporções, mostram a onipresença da tristeza, do sofrimento e da inevitável finitude.

A televisão se coloca como um perfeito mirante, amplo e abrangente, de que se pode olhar com precisão e ouvir em detalhe palavras proferidas ou até mesmo pensamentos envoltos nas angústias vividas na intimidade ou em campo aberto, transbordadas ao social. "Na arte, a sublimação se refere aos processos psicológicos de transformação, em que experiências ordinárias e pouco significativas se convertem em algo nobre e refinado" (DE BOTTON; ARMSTRONG, 2014, p. 26). A televisão também cumpre esse papel e, por sua alta frequência de consumo, permite o contato diário com o potencial transformador, empático ou reflexivo de histórias com ou sem finais felizes, tanto na ficção das telenovelas e filmes quanto na realidade dos telejornais.

\section{A TV como reequilíbrio}

Raros são os que têm pleno equilíbrio. Nossa biografia psicológica, as relações e rotinas de trabalho fazem com que emoções se inclinem seriamente mais para um lado do que para outro. Podemos, por exemplo, tender a ser presunçosos ou inseguros demais, confiantes ou desconfiados demais, frívolos ou sérios demais. (DE BOTTON; ARMSTRONG, 2014, p. 32)

A busca pelo equilíbrio é uma das grandes temáticas da atualidade. Queremos manter uma equidade entre o trabalho e o descanso, entre o tempo em que temos que realizar tarefas corriqueiras e o dedicado à família ou aos amigos. Somos incentivados a dominarmos nossas carreiras, idealizando uma trilha de sucesso, ao mesmo tempo que somos pressionados a nos reconectar com a natureza e com as coisas simples. No entanto, tal balanceamento perfeito não existe ou, se existe, acontece com poucos afortunados ou em momentos muito específicos. Somos bela e naturalmente imperfeitos, mas ansiamos e somos cobrados pela perfeição, 
como bem atesta Han (2015) ao afirmar que "a sociedade do século XXI não é mais a sociedade disciplinar, mas uma sociedade de desempenho” (p. 23).

A televisão nos entrega a possibilidade de entrarmos em contato com o que nos falta ou o que acreditamos que nos falta, em um processo contínuo de busca-satisfação-erosão-nova busca. E como essas falhas ou lacunas não são iguais para todos nós, a diversidade do conteúdo televisivo se apresenta como um cardápio amplo e variado de peças complementares, em que buscamos diferentes possibilidades. Tais conteúdos podem ser de natureza moral, ética, espiritual, estética, educacional ou psicológica, por exemplo. Encontramos histórias na TV com as quais nos identificamos, de pessoas que passaram pelos mesmos dilemas que recheiam nossas vidas e para os quais acreditávamos que não haveria solução. Temos a oportunidade de comungar de alguma fé ou visão de mundo que não conhecíamos. Vivendo em ambientes urbanos contaminados pela poluição, pela superlotação dos transportes públicos e pela raridade de áreas verdes, podemos ser transportados para cenários paradisíacos, para florestas nas quais a natureza pulsa ou para o silencioso fundo de algum oceano.

A televisão nos permite buscar ou simplesmente encontrar casualmente o que nos falta, ajudando-nos a calibrar a balança das nossas emoções e da nossa psique. Podemos dizer que "o equilíbrio simbolizado pela balança indica um retorno à unidade [...]. 0 equilíbrio realizado pelos pratos fixados um diante do outro, portanto, significa uma posição para além do conflito, que pertencem ao tempo-espaço, à matéria” (CHEVALIER; GHEERBRANT, 1993, p. 114), ainda que esse equilíbrio tenha a natureza da provisoriedade (PEREZ, 2004).

A sociedade contemporânea nos oferece, ainda, uma infinidade de distrações e estímulos, cobrando produtividade, multitarefas e otimizações, incentivando interações constantes nas mídias sociais ou nos aplicativos de comunicação, criando parâmetros do que é ter sucesso ou ser feliz. A televisão pode ser a porta de acesso para um momento pessoal, seja para relaxar, distrair, reconfortar, conectar, experimentar, escapar, aprender a fazer ou uma simples recompensa (THINKBOX, 2018), por isso também se revela como possibilidade de reequilíbrio.

\section{A TV como compreensão de si}

Certamente somos as únicas pessoas que nos conhecemos em primeiríssima experiência, com total acesso à mais profunda intimidade, mas isso não nos isenta de termos mistérios para e sobre nós mesmos. A psicanálise é a ciência que mais nos ajuda a nos compreendermos, apoiada na descoberta do inconsciente e de como não somos tão racionais e controladores dos nossos pensamentos e atitudes como podemos pensar. Os autores De Botton e Armstrong (2014) nos dizem que não somos transparentes para nós mesmos: "temos intuições, suspeitas, palpites, vagas reflexões e emoções estranhamente contraditórias, e tudo isso resiste a uma definição simples. Temos estados de espírito que não conhecemos bem” (p. 47). Em meio a essa condição naturalmente fugidia, topamos com conteúdo, histórias, matérias, cenas que parecem agarrar algo que sentimos, mas que nunca havíamos notado com clareza. Nos tocam pela identificação com algo que nos sensibiliza.

Quando sentimos afinidade com um tema, uma história, uma pessoa ou um personagem, é porque os valores que ali sentimos presentes são mais claros nele do que costumam ser para nós. (DE BOTTON; ARMSTRONG, 2014, p. 47) 
O leque de opções de consumo de conteúdo audiovisual cresce velozmente e, a cada dia, surgem novos aplicativos, sites e plataformas à disposição no Brasil e no mundo. Netflix, Globoplay, Amazon Prime, Disney+, YouTube, TikTok e Hulu, só para citar alguns dos caminhos possíveis, dão acesso de forma gratuita ou paga a uma miríade de vídeos, das mais diferentes durações e origens. Esses entrantes engrossam o já estabelecido cenário de possibilidades das TVs abertas e por assinatura e, independentemente do modelo de negócios - pago, gratuito, com ou sem publicidade - todos disputam o limitado tempo dos consumidores.

E esses consumidores, por sua vez, com a tal limitação de tempo, dedicam sua atenção, escolhendo histórias e personagens para seguir por segundos ou meses, compartilhando tal experiência com quem está ao seu lado no sofá, como assunto para quebrar o gelo em uma reunião ou em qualquer rede social. Tais histórias são, em algum nível, parecidas com os próprios consumidores, com suas vidas, medos, alegrias e humores.

A TV desenvolve o autoconhecimento e é uma excelente maneira de falarmos de nós mesmos para outras pessoas. Partilhar nossa experiência midiática é contar o que nos toca e permitir que os outros nos conheçam melhor, e aí reside a possibilidade da televisão como compreensão de quem somos, a partir do fenômeno da identificação.

\section{A TV como crescimento}

$\mathrm{O}$ atual mundo dos algoritmos promete nos fazer recomendações assertivas a partir de nossas experiências anteriores, do nosso histórico de navegação ou de como pessoas que têm interesses parecidos com os nossos se comportaram (ou compraram). Somos poupados do contraditório e de nos depararmos com conteúdos que fogem dos padrões ditados por análises probabilísticas. Trafegamos, assim, por ambientes confortáveis, pavimentados para criar experiências felizes e em que sabemos o que esperar. Se assistimos a algumas comédias românticas em alguma plataforma por assinatura de conteúdo audiovisual, por exemplo, seremos constantemente direcionados às novas aquisições ou produções desse gênero. Nesse sentido, a televisão também colabora para o excesso de positividade, na linha das reflexões críticas de Han (2017).

No entanto, não passaremos intactos pela vida sem nos confrontarmos com temáticas e situações desagradáveis. De Botton e Armstrong (2014) nos dizem que isso faz parte do mundo da arte, ao afirmarem que "a aversão a algum gênero de arte pode nascer de experiências de fato traumáticas” (p. 50), sinalizando ainda que podem incitar combinações de medo a tédio. Em um museu que abraça diversas coleções, por exemplo, transitamos por diferentes períodos e estilos. Sentimos familiaridade ou proximidade de alguns por nossa história familiar, estudo, ascendência, formação religiosa ou espiritual, ou empilhamento de experiências anteriores. Em sentido oposto, somos mergulhados em um estado de estranhamento ou colocados em posição defensiva quando nos deparamos com quadros, instalações ou esculturas que conflitam com nossas crenças ou apresentam padrões estéticos incomuns.

"A arte que começa nos parecendo estranha e é valiosa porque nos apresenta ideias e atitudes que dificilmente encontraríamos em nosso ambiente costumeiro e que nos são necessárias para termos pleno envolvimento com nossa humanidade” (DE BOTTON; ARMSTRONG, 2014, p. 58), os autores afirmam, apontando que crescemos por meio do contato com o desconhecido, o que nos irrita ou o que nos provoca. 
Dentro de uma previsibilidade de gêneros, a televisão nos coloca diariamente em frente a conteúdos, linguagens, situações ou estéticas que nos surpreendem. Sessões de filmes variam sua programação entre blockbusters, indicações ou premiados no Oscar, filmes de ação, comédias, produções independentes, séries e minisséries, nacionais ou internacionais, todas com a potencialidade de provocar o olhar e a imaginação do público ao usar material reciclado como cenografia e figurino, como A Pedra do Reino, veiculada na Globo em 2007, ou ao trazer feitiços e seres imaginários, como Game of Thrones, veiculada na HBO em 2011, ou ainda o encantamento do realismo fantástico da telenovela Saramandaia, exibida pela primeira vez em 1976 e com direito a remake em 2013. As telenovelas, mesmo dentro de um modelo folhetinesco, abusam de novidades e provocações, que vão das produções turcas, como Fatmagul - A Força do Amor, exibida na Band entre 2015 e 2016, ao famoso beijo gay na novela Amor à Vida, exibida na Globo entre 2013 e 2014.

A televisão nos possibilita depararmos com assuntos ou temáticas com as quais não estamos habituados ou até não gostaríamos de lidar. Preconceito, visões parciais ou julgamentos superficiais fazem parte da nossa vida e os conteúdos disponíveis na televisão nos oferecem a oportunidade de refletir sobre eles na nossa intimidade e crescer.

\section{A TV como apreciação}

Uma das nossas maiores falhas e causas da infelicidade que sentimos provém de considerarmos difícil perceber o que sempre está ao nosso redor. Sofremos porque não vemos o valor do que está diante de nós e suspiramos, muitas vezes injustamente, pelas atrações imaginárias de outro lugar. (DE BOTTON; ARMSTRONG, 2014, p. 59)

A TV, com sua pluralidade de conteúdos, oferece ao público canais, programas ou quadros que glorificam as celebridades, mostrando glamour e um estilo de vida inalcançável para a maioria dos mortais. Apresentadores especializados comentam romances entre casais de beleza ímpar, festas com estrelas da música nacional e das telenovelas ou a aquisição de mansões dos sonhos em lugares paradisíacos.

É um mundo de aparente felicidade, de pessoas que convertem fama em dinheiro e de festas sem fim. Tudo que está fora do alcance da grande maioria dos telespectadores. Anualmente, a transmissão das principais cerimônias de premiação do cinema e da televisão americana e internacionais, como o Oscar, o Grammy e o Festival de Cannes, por exemplo, tem o seu momento red carpet, quando as celebridades desfilam e tiram fotos ao longo de um tapete vermelho, enquanto comentaristas, apoiados por assessorias de imprensa, apontam de qual costureiro ou maison é determinado vestido, de qual joalheria é aquele colar e assim por diante.

A partir dessa perspectiva, nossa vida poderia ser entendida como monótona e desinteressante, com uma rotina doméstica repetitiva e, para os hoje até afortunados, com o ritual de casa-trabalho-casa. Se há brilho na vida, ou ele vem de vivenciar experiências de consumo, de sinalizadores de status, ou de assistir à vida deslumbrante, intrigante e até moralmente desafiadora dos famosos.

No entanto, a televisão, além de vitrine para o mundo descrito acima, é também alerta e consciência, convidando-nos a reavaliar o que 
realmente é valioso, ressignificando o que merece nossa admiração. Ela nos reapresenta o mundo cotidiano com um olhar diferente, nos lembra de dar valor às coisas simples da vida e nos ajuda a relevar as imperfeições. Como exemplo, o telejornal Bom Dia SP apresenta semanalmente o Quadro Verde, no qual a repórter Ananda Apple mostra, muitas vezes, árvores e plantas que estão espalhadas pela cidade e que passam incólumes à apreciação e também à atenção dos transeuntes. O jornalista Carlos Tramontina, por sua vez, no programa Antena Paulista, acolhe os telespectadores aos domingos pela manhã com um singelo cafezinho e um bolo caseiro.

De Botton e Armstrong (2014) afirmam que "faz parte do poder da arte homenagear o valor esquivo, mas real da vida comum” (p. 62) e, com esse mesmo direcionador, a televisão pode nos mostrar que está ao nosso alcance fazer o melhor possível com a limitação de recursos de proventos exíguos e com as dores, frustrações e cicatrizes coletadas ao longo da jornada da vida. As histórias das telenovelas, realities, programas de auditório ou telejornais podem "nos redespertar para o autêntico mérito da vida que somos obrigados a levar" (DE BOTTON; ARMSTRONG, 2014, p. 62).

\section{CONSIDERAÇÕES FINAIS}

Como já foi mencionado ao longo deste texto, a televisão pode satisfazer diferentes necessidades pessoais dos telespectadores consumidores, seja em um momento de relaxamento, distração, reconforto, conexão, experimentação, escapismo, aprendizado ou uma simples recompensa. Mas a televisão pode muito mais do que isso, em uma multiplicidade de sentidos em geral pouco explorada, uma vez que os espaços da crítica sobre a manipulação predominam, ainda que em sua maioria pertinentes, sobre as reflexões de suas potencialidades.

Tal como na arte, é possível fazer uma leitura do conteúdo dos programas e da programação da televisão a partir de questões técnicas como iluminação, cenografia e enquadramento. Também é comum trazer à tona um olhar político, principalmente nos editoriais e abordagens dos telejornais. Há, é claro, uma leitura histórica, tendo o arquivo da televisão como uma galeria audiovisual das mudanças e evoluções da estética e da linguagem, do que era vanguarda, do que se sedimentou e o que se perdeu no tempo.

Assim, a aproximação da proposta de De Botton e Armstrong (2014), realçando a perspectiva artística da televisão, nos abriu espaço para fazer as associações que permitiram o entendimento da televisão como rememoração, esperança, sofrimento, reequilíbrio, compreensão de si, crescimento e, finalmente, apreciação. Sem a intenção de esgotar os múltiplos sentidos e tampouco aprofundar a dimensão crítica, sempre necessária, propusemos aqui outro olhar, articulando o viés da arte e seus efeitos sobre nossa subjetividade. Nesse sentido, as discussões sobre a qualidade do conteúdo apresentado em determinado canal, programa ou quadro televisivo pode ficar em segundo plano quando se traz a reflexão sobre o efeito que potencialmente pode ter causado no telespectador. Padrões estéticos de bom ou mau gosto passariam a ser coadjuvantes em um processo permanente de auto investigação e reflexão sobre o papel da comunicação, dos dispositivos e plataformas na construção da nossa identidade e condição de existência contemporânea, certamente midiatizada. 


\section{REFERÊNCIAS}

ARISTÓTELES. Metafísica. São Paulo: Loyola, 2002.

BRENNAN, David. TV conectada: como as qualidades analógicas da TV criaram uma supermídia digital. São Paulo: Globo, 2016.

BRIGGS, Asa; BURKE, Peter. Uma história social da mídia: de Gutenberg à Internet. 3. ed. Rio de Janeiro: Zahar, 2004.

CHEVALIER, Jean; GHEERBRANT, Alain. Dicionário dos símbolos: mitos, sonhos, costumes, gestos, formas, figuras, cores, números. Rio de Janeiro: José Olympio, 1993

DE BOTTON, Alain; ARMSTRONG, John. Arte como terapia. Rio de Janeiro: Intrínseca, 2014.

EAGLETON, Terry. Humor: o papel fundamental do riso na cultura. Rio de Janeiro: Record, 2020

ECO, Umberto (org.). História da beleza. Rio de Janeiro: Record, 2004

FARTHING, Stephen (ed.). Tudo sobre arte. Rio de Janeiro: Sextante, 2011.

GITLIN, Todd. Mídias sem limite: como a torrente de imagens e sons domina nossas vidas. Rio de Janeiro: Civilização Brasileira, 2003.

HAN, Byung-Chul. Sociedade da transparência. Petrópolis: Vozes, 2017.

HAN, Byung-Chul. Sociedade do cansaço. Petrópolis: Vozes, 2015.

JENKINS, Henry; FORD, Sam; GREEN, Joshua. Spreadable media: creating value and meaning in a networked culture. New York: New York University Press, 2013.

MACHADO, Arlindo. A televisão levada a sério. São Paulo: Senac, 2000.

MCLUHAN, Marshall. Os meios de comunicação como extensão do homem. São Paulo: Cultrix, 1964.

NEGROPONTE, Nicholas. A vida digital. São Paulo: Companhia das Letras, 1995.

PEREZ, Clotilde. A comunicação da completude: a busca do objeto do desejo. Revista Mackenzie: Educação, Arte e História da Cultura, São Paulo, v. 3-4, p. 109-116, 2004.

PEREZ, Clotilde. Há limites para o consumo? São Paulo: Estação das Letras e Cores, 2020.

PEREZ, Clotilde. Signos da marca: expressividade e sensorialidade. 2. ed. São Paulo: Cengage Learning, 2017.

SANTAELLA, Lucia. Comunicação ubíqua: repercussões na cultura e na educação. São Paulo: Paulus, 2013.

SANTAELLA, Lucia. Linguagens líquidas na era da mobilidade. São Paulo: Paulus, 2007.

SCHOPENHAUER, Arthur. Dores do mundo. Rio de Janeiro: Ediouro, 1985.

THINKBOX. The age of television: the needs that drive us. Thinkbox, London, 2018. Disponivel em: https://www.thinkbox.tv/research/thinkbox-research/the-age-of-televisionthe-needs-that-drive-us/. Acesso em: 1 jun. 2021.

WEEMS, Scott. A ciência do humor. São Paulo: DVS, 2016.

WILLIAMS, Raymond. Televisão: tecnologia e forma cultural. São Paulo: Boitempo; Belo Horizonte: PUC Minas, 2016 